\title{
Persona, colectivo y ciudadanía en los saraus de las periferias de São Paulo
}

\author{
Pessoa, coletivo e cidadania nos saraus das periferias de São Paulo
}

Lucía Tennina

RMA

Dossier
CONICET, Instituto de Literatura Hispanoamericana, Facultad de Filosofía y Letras, Universidad de Buenos Aires. E-mail:Iuciatennina@gmail.com

\section{Resumen}

En este artículo trabajo alrededor de los usos de la noción de "literatura" en los saraus de las periferias de São Paulo. La literatura, dentro de esos espacios, es considerada, por un lado, como un medio facilitador para proyectar ser una "persona" con una valoración específica en el marco de un colectivo que le otorga protección y promueve el desarrollo de un sentimiento de pertenencia. Además, la palabra literaria es considerada, según esta lógica, como un mediador en el proceso de constitución de un "ciudadano", entendiendo esa idea desde una idea de "ciudadanía cultural", esto es, a partir un tipo de representación que considere las pertenencias y los anclajes culturales como componentes indisociables de su definición.

Palabras clave: saraus; periferia; São Paulo; persona; ciudadanía

\begin{abstract}
In this article I work around the uses of the notion of "literature" in the saraus of the peripheries of São Paulo. Literature, within these spaces, is considered, on the one hand, as a facilitating means to project to be a "person" with a specific valuation, within the framework of a collective that grants protection and promotes the development of a sense of belonging. In addition, the literary word is considered, according to this logic, as a mediator in the process of constitution of a "citizen", understanding that idea from an idea of "cultural citizenship", that is, a representation that considers the belongings and cultural anchorages as inseparable components of their definition.
\end{abstract}

Keywords: saraus; periphery; São Paulo; person; citizen

Todos los miércoles la esquina del bar de Zé Batidão se encuentra colmada de gente. Algunas personas con libros en las manos, otras con vasos, otras con papeles o cuadernos manuscritos, todas beben y conversan como en cualquier bar frecuentado por gente que en su mayoría se conoce entre sí. Pero hay una diferencia: esperan un evento especial que tendrá lugar ese día, el Sarau da Cooperifa. No solo ocupan el interior del bar, sino también la vereda e incluso la calle. Es que el bar no es suficiente para contener a todos los poetas, frecuentadores e interesados que se acercan al sarau. Pese a que hay dos largas mesas y varias otras más pequeñas, la mayor parte de la gente está de pie, porque encontrar un lugar para sentarse resulta imposible si uno no llegó muy temprano. Hay un solo espacio liberado, que está al costado de la entrada, al frente de todas las mesas: el del micrófono. El bullicio y el ir y venir de los asistentes es intenso, hasta que una voz amplificada empieza a imponerse y a pedir silencio.

El Sarau da Cooperifa abre comandado por la palabra de Sérgio Vaz, que acompaña inquieto cada frase con unos saltos en el lugar. Los presentes, que esperan que el sarau comience, poco a poco hacen silencio, mientras Sérgio, entre palabra y palabra, los mira fijo y dice:

Sejam todos bem-vindos ao Sarau da Cooperifa! Movimento cultural de periferia para a periferia, que acontece às nove horas aqui no bar do Zé Batidão! Saibam... que TODOS SÃO bem-vindos, TODOS, de todos os lugares, todas as cores, todas as crenças. Só tem uma regra aqui: o silêncio é uma prece! E é uma prece mesmo! Não é uma balada, é um movimento, certo? Muito respeito para o que se está fazendo aqui na periferia, no extremo sul de São Paulo. Hoje, viemos aqui para comungar a palavra, a poesia. Por isso, exigimos res-pei-to!!! Então, eu queria agradecer. Estamos muito felizes de estar aqui com vocês novamente na quebrada, trazendo tudo de bom que a gente pode levar, vivendo um novo momento da periferia. As pessoas da periferia alta estima, pretos, brancos, pobres, que não somos racistas, todos aqueles que entendem mais ou menos o processo que é o povo pobre da periferia do Brasil. Mas é por isso nós vamos ficar aqui reclamando? Sem con-versa! Certo? Não reproduzimos preconceitos, certo? 
Firmeza? Não! Chega chegando, é festa de favela, res-pei-to! Povo lindo! Povo inteligente! É tudo nosso!!! "Uh, Cooperifa! Uh, Cooperifa!".

Todos los miércoles de cada año desde octubre de 2001, Sérgio Vaz expresa este mensaje con mínimas variaciones para dar inicio al sarau. Se empieza a llamar luego a los poetas que se habían anotado en una lista donde figuran los que van a declamar esa noche. Se los llama por el nombre y por más que no sean conocidos entre los asistentes, la mención siempre dispara aplausos. Cuando se trata de asiduos frecuentadores, se los llama por el nombre con el agregado de "poeta", "guerreira", "guerreiro", "irmã", "da família". Cuando quien pasa a declamar es un visitante externo, suele hacerse una presentación celebratoria de la persona, dando a entender, de otro modo, lo que se dijo en las palabras de bienvenida: "Todos são bem-vindos".

Entre poeta y poeta Vaz a veces repite las frases "Povo lindo! Povo inteligente!", que los participantes corean y cierran con el grito de "Uh! Cooperifa! Uh! Cooperifa!". En otros momentos recuerda que hay que hacer silencio: "Pessoal aí, do fundão, vamo colaborar, firmeza, tem parte de poeta que já falou indo para lá e fica numa de não respeitar, o silencio continua sendo uma prece".

Quien organiza el sarau no es solamente Sérgio Vaz. Hay un equipo detrás que se reparte las tareas: en primer lugar, anotar los nombres de las personas que quieren declamar esa noche, luego, cumplir con el orden de esa lista, presentar a los poetas, pedir silencio cuando lo creen necesario y controlar el tiempo de duración de las declamaciones. "23 horas nós paramos, firmeza? Então, a lista está enorme, sejamos generosos com os últimos, firmeza? Vamos fazer a poesia mais curtinha".

La duración de las declamaciones no está cronometrada (a diferencia de lo que ocurre en un slam ${ }^{1}$ ) pero, de todos modos, no es común que quien declama se extienda demasiado, dado que los frecuentadores de saraus han ido incorporando un reglamento implícito marcado por una especie de reloj interno que controla el tiempo de la presentación. Los límites entre los oyentes y quienes declaman durante el evento, como podemos ver a partir de este ejemplo, son dinámicos, dado que en un sarau la misma persona puede estar alternativamente en una u otra posición y, además, hay un grado de familiaridad que achica las distancias que suele haber entre un artista y el público, de ahí que no se hable de público y se denomine a los presentes como "frecuentadores" o como participantes.

Otra función de los organizadores es alentar las hurras y los aplausos al final de cada declamación. Los poetas y los

\footnotetext{
${ }^{1}$ El slam de poesía es un torneo de competencias poéticas, los poetas ponen en escena su texto frente a un público durante un lapso previamente especificado y resultan ganadores aquellos elegidos de acuerdo con la resolución de un jurado.
}

participantes que se acercan al sarau saben que, si pasan a recitar, serán aplaudidos y no se evaluará la rigurosidad estética de su declamación. Explica al respecto Sérgio Vaz:

Então, a gente trata as pessoas comuns, por isso que o aplauso é igual, se chama da mesma forma. A gente procura sempre evitar aplaudir mais um do que o outro. Não existe o melhor da noite. O Seu Lourival que é uma pessoa simples é tão aplaudido quanto o Rodrigo Ciriaco, que é um professor. E assim que a gente vai... (Entrevista personal, 2010)

Es así que toda persona que pase a declamar es considerada "poeta" y se autoidentifica a sí misma bajo esa denominación. La poesía es el género protagonista, aunque en menor medida también hay crónicas o cuentos cortos.

Una característica del Sarau da Cooperifa, a diferencia de otros saraus, es que se estructura bajo la estricta consigna de que el micrófono sirva solo a la literatura. Recién cuando el sarau termina, aparece la música instrumentada, no antes. Wesley Nóog es quien suele musicalizar el cierre cantando acompañado por su guitarra. Mientras Wesley canta², los asistentes se paran y comienzan a bailar y el personal del bar corre las mesas y las sillas anticipando el inminente cierre. Sérgio Vaz generalmente saca fotos o baila con Dona Edite, una asidua participante, anciana y ciega, que se sienta siempre justo frente al micrófono Apenas termina la canción, la gente empieza a irse. El bar de Zé Batidão no mantiene el espacio como para que se extienda la reunión, solamente deja una mesa larga donde quedan Vaz, su esposa Sonia, los poetas y organizadores Marcio Batista, Jairo Periafricania, Rose Dorea, Cocão y algún que otro invitado del día.

El sarau termina casi puntualmente a las 23 y la justificación del horario está orientada a reforzar las ideas de respeto y de comunidad. Comenta Sérgio Vaz en la entrevista recién citada:

Tem um problema aqui, que é a comunidade. Nós temos um acordo com eles que é acabar o sarau às 11 horas. Então, se a gente vai fazer alguma coisa para enaltecer à comunidade, você não pode começar agredindo a comunidade. E duas horas também é um tempo bom, porque a gente não vem aqui só pra beber. A gente vem para ouvir e falar poesia. Na hora em que acabou, acabou. E aí fica um gosto de "quero mais" para outra quarta-feira, não é? E aqui é aberto, está vendo? Se a gente fica até uma, duas da manhã, eu acho que perde um pouco de sentido do que a gente vem fazer aqui. E aí as pessoas começam a vir aqui só pra beber. E a gente quer que as pessoas

\footnotetext{
2 La descripción aquí realizada se basa en los registros recogidos durante el trabajo de campo llevado a cabo en los saraus los años 2010 y 2011 . En la actualidad ya no hay música al comienzo y al final del sarau a fin de enfatizar el perfil de Cooperifa que se caracteriza por ser estrictamente literario.
} 
venham para ouvir e falar poesia. (Entrevista personal, 2010)

Esta actitud estricta en relación con el horario subraya que el encuentro literario no se basa en el ocio sino que está pensado como un proyecto bien estructurado que tiene como eje central a la idea de que los participantes logren legitimar sus posicionamientos de sujeto a nivel individual y colectivo:

Este é um projeto que visa a levar autoestima $e$ cidadania à comunidade através da literatura. $\mathrm{E}$ muitas pessoas mudaram! Por exemplo, Seu Lourival quando chegou aqui tinha o cabelo branco. Hoje ele pinta os cabelos: a autoestima lá em cima. A gente tem garoto que tinha parado de estudar: voltou a estudar, terminou a faculdade e a tese foi sobre a Cooperifa. Então, tem pessoas que, incentivadas pela Cooperifa, direta ou indiretamente, começaram a sentir a necessidade de progredir intelectualmente. Mas isto é uma coisa da pessoa. A gente não fala pra ela: "Volta a estudar!" Ninguém cuida da vida de ninguém. Mas o lugar intensifica que as pessoas tenham essa magia de querer mais. E o querer mais não é aqui, é em outros lugares. Aqui é um lugar para a gente se reunir. (Entrevista personal, 2010)

La literatura, de acuerdo con esta lógica, es considerada, por un lado, como un medio facilitador para proyectar ser una "persona" ligada a un "yo" que tiene una conciencia de sí mismo y una valoración específica en el marco de un colectivo que le otorga protección y promueve el desarrollo de un sentimiento de pertenencia. Por otro lado, la palabra literaria es considerada, según esta lógica, como un mediador en el proceso de constitución de un "ciudadano" en tanto, puede posibilitar una serie de garantías y experiencias sociales (la educación y el acceso a la lectura, por ejemplo) que contribuyan en la reducción de las desigualdades sociales.

\section{La persona literaria}

El Sarau da Cooperifa, creado por los poetas Sérgio Vaz y Marco Pezão en 2001 fue el primer sarau de la periferia de São Paulo. A partir de entonces en las regiones suburbanas de esa ciudad vienen organizándose cada vez más saraus, que hoy han de ser más de $50^{3}$. Año a año su número se multiplica, llena el calendario día por día y salpica el mapa de este tipo de eventos.

Una idea central que estructura las producciones de los saraus se vincula con la literatura entendida como un territorio específico de culto a la autoestima de los habitantes de la periferia. Tanto la producción poética de muchos frecuentadores como sus declaraciones durante

\footnotetext{
3 Según Agenda da Periferia, www.agendadaperiferia.org. br/\#literatura, consultada setiembre 2015.
}

los saraus insisten en la concepción de la literatura ligada al cultivo de las capacidades y motivaciones individuales censuradas generalmente por la idea de carencia que suele asociarse a la condición de vivir en los barrios más pobres y estigmatizados de la ciudad. El interés se centra, en este sentido, en el cultivo no tanto de los artificios literarios ${ }^{4}$ y el trabajo alrededor del erigirse como poeta, sino que pasa por el cultivo de la persona a partir de la poesía. Dice al respecto Sérgio Vaz:

Este sarau [da Cooperifa] é um projeto que visa levar autoestima à comunidade. (...) A gente não quer que nasça um monte de poetas. A gente quer que nasça um monte de pessoas. "Ah, eu não sei escrever..." Não importa. A gente quer trazer poetas na atitude, no coração, na forma de agir, e não na escrita. (Entrevista personal 2010)

En el caso del sarau, el fortalecimiento de la estima por sí mismo de cada participante empieza por la adquisición de un papel específico que cada uno alcanza en ese encuentro literario basado en su propia persona, entendida en el mismo sentido que prósopon ( $\pi \rho$ ó $\sigma \omega \pi \mathrm{ov})$, término griego que conserva un significado ligado a lo que está detrás de la máscara, la intimidad de una persona. "Entende-se a palavra $\pi \rho$ ó $\sigma \omega \pi$ ov ao indivíduo em sua natureza nua, arrancada toda máscara, conservando-se, em contraposição, o sentido do artifício: o sentido do que é a intimidade dessa pessoa e o sentido do que é personagem" (Mauss 2003 b: 390). Es sobre esos elementos personales que se entiende la idea de poeta de un sarau en la periferia y la propia producción de sus frecuentadores. Ser poeta en el sarau no implica, en este sentido, tener una trayectoria letrada. Según Érica Peçanha do Nascimento, antropóloga pionera en estudiar estos espacios: "O título de poeta é uma espécie de reconhecimento comunitário, autoatribuido e imputado pelos pares do sarau em consideração ao vínculo criado e assiduidade de participação" (2011: 76). Ser poeta tiene que ver, así, con la fidelidad respecto del sarau y para con la propia persona.

El ya mencionado Seu Lourival [Lourival Rodríguez], por ejemplo, fue un asiduo frecuentador del Sarau da Cooperifa (hasta enero de 2015, cuando falleció) que, sin haber publicado nunca ningún libro, ganó el mote de "poeta". Nacido en el Nordeste de Brasil (Riacho de Santana, Estado de Bahia) y habitante de la periferia zona sur de São Paulo, fue una marca registrada del Sarau, entre otras tantas figuras. No había sarau en el que él no estuviese. Y, cada vez que Lourival se acercaba al micrófono, los presentes sabían que iban a escuchar algún poema rimado y con un yo lírico que se dirigiese a una mujer y sabían también que alguna sonrisa o carcajada iban a emitir, dado que siempre tenía su toque

\footnotetext{
${ }^{4}$ No es el foco de este artículo, pero es importante dejar en claro que existe sí una preocupación estética en estos espacios. Para un análisis en ese sentido ver http://periodicos.unb.br/index.php/estudos/article/ view/9989
} 
de humor. Además, en general convocaba a los presentes a participar de su declamación de alguna manera. "Eu queria que chuvesse uma chuva bem fininha/ Pra molhar a sua cama pra você dormir na minha" dijo en medio de una declamación en un sarau del 2010, palabras que pertenecen al conocidísimo coco alagoano (ritmo típico del nordeste brasileño, región originaria del poeta) llamado "Dona Mariquinha", de Mestre Verdelinho. Lourival construyó en el marco del sarau una "fachada personal" 5 en base a su historia personal ligada a su timidez, por un lado, y a la cultura del nordeste, por otro, adquiriendo así un estatus, una posición reconocible y valorizable dentro de ese mismo universo, que lo llevaba a ser reconocido como "poeta".

El sarau no solamente es un espacio para declamar poemas, sino que consiste en una pauta de acción preestablecida en la que muchos de los asistentes logran un rol determinado a partir de su propio lenguaje expresivo tanto corporal, como de estilo y de aspecto. Cada uno de los frecuentadores de los saraus de poesía de la periferia tiene un papel en ese contexto que, cabe aclarar, no se forja solamente a partir de su asistencia sino que se modela en la interacción con la información previa que el individuo posee y que forma parte de su biografía personal.

Al notar la tendencia del participante a aceptar las exigencias de definición hechas por los otros presentes, podemos apreciar la importancia decisiva de la información que el individuo posee inicialmente o adquiere sobre sus coparticipantes, porque sobre la base de esta información inicial el individuo comienza a definir la situación e inicia las reglas correspondientes de acción (Goffman 2009: 24-25).

La historia de vida de los poetas se capitaliza en el contexto del sarau, incluso el propio barrio de residencia deja de causarle inseguridad sobre una gran variedad de interacciones sociales (Goffman 2010: 27), se valoriza y se vuelve un capital de naturaleza simbólica. De acuerdo con los testimonios de muchos poetas, mientras que antes no se animaban a decir dónde vivían, hoy en día se sienten orgullosos de decir "vivo cerca de tal sarau". Los saraus funcionan, en este sentido, como un artefacto cultural influyente en la potencialidad de una vida en la periferia. La historia de vida de los participantes adquiere en ese contexto un perfil cultural y los elementos que antes eran estigmas se vuelven recursos simbólicos positivamente sancionados.

El origen nordestino que también es causa de sufrimientos por juicios raciales y morales, por ejemplo, se hace presente en los saraus desde una sonrisa pícara y una

\footnotetext{
5 "Fachada" es, según Ervin Goffman, "la parte de la actuación del individuo que funciona regularmente de un modo general y prefijado a fin de definir la situación con respecto a aquellos que observan dicha actuación [...]". Y fachada personal, "los otros elementos de esa dotación, aquellos que debemos identificar íntimamente con el actuante mismo" (2009 pp, 36 y38).
}

declamación rimada en forma de poesía de cordel que algún vecino del nordeste o hijo de nordestino declama de memoria durante largos minutos. La negritud, vivida en el día a día desde el racismo, se vuelve en dichos espacios una fuerza ancestral expresada muchas veces como rap que, cuando son declamados por hombres, se recitan mostrando sus cuerpos erguidos, sin sonrisas ni expresiones sensuales, y con claros gestos de hostilidad ${ }^{6}$. El cansancio corporal producto de largas horas arriba de un transporte público que todo trabajador de la periferia soporta diariamente los expresa una mujer con la declamación de una "pichação"7 captada el camino en una pared de la ciudad, "todos caem, mas só os fracos continuam caídos". La realidad de un profesor de las regiones suburbanas que suele ver cómo sus alumnos dejan la escuela para entrar en el tráfico de drogas, aparece en los saraus en forma de relato enfatizado con los puños golpeando el pecho y las manos en forma de ele imitando un arma. Una vida entera en un barrio periférico se traduce en un poema dedicado cara a cara por un hombre mayor a Dona Edite, una vecina que está sentada frente al micrófono (una mujer ciega que asiste todas las semanas al sarau de su barrio). Las perseguidas prácticas de las religiones afro-brasileñas ${ }^{8}$, como el candomblé, se hacen presentes en forma de canto en voz de una mujer negra que se arrodilla al nombrar a un orixá en particular acompañando sus palabras con las manos ${ }^{9}$. Se pueden citar cientos de ejemplos, cada persona que se acerca a un sarau expresa su identificación con la "periferia" no solo con los textos sino también con el cuerpo, exhibiendo así sus aspectos corporales y del habla como bienes de naturaleza simbólica (Bourdieu 1997: 108).

\section{Mecanismos colectivos de legitimación de la palabra}

Es importante dejar en claro en este punto que el trabajo de los saraus no pasa por la adquisición de la palabra, sino alrededor de la posibilidad de "hablar con autoridad". Como afirma Regina Dalcastagnè: "O fundamental é perceber que não se trata apenas da possibilidade de falar-que é contemplada pelo preceito da liberdade de expressão, incorporado no ordenamento legal de todos

\footnotetext{
${ }^{6}$ Esta corporalidad evidencia lo mismo que Maria Rita Kehl presenció en un show de los Racionais Mc's: "Há uma mudança de atitude, partindo dos rapers e pretendendo modificar a autoimagen e o comportamento de todos os negros pobres do Brasil: é o fim da humildade, do sentimento de inferioridade que tanto agrada à elite da casa grande, acostumada a se beneficiar da mansidão -ou seja, do medo" (Kehl apud Salles:136)

7 "Pichar" es escribir en los muros o paredes públicas con una letra de trazos rectos incomprensible para el ojo acostumbrado a la caligrafía tradicional.

8 "Levantamentos mostram perseguição contra religiões de matriz africana no Brasil", http://oglobo.globo.com/sociedade/ levantamentos-mostram-perseguicao-contra-religioes-de-matrizafricana-no-brasil-13550800 [Acceso setiembre 2015]

${ }^{9}$ Como señala De Certeau en relación con los gestos de oración: "Las manos llevan en sí una inteligencia de las cosas cotidianas y saben de las ternuras o las labores que carecen de nombre; también tienen la capacidad de decir aquello para lo cual el intelecto todavía no tiene o ha dejado de tener vocabulario. Sólo aprietan el vacío: no obstante, lo que designan no es la ausencia, sino una aspiración o una certeza de la fe" (2006: 36)
} 
os países ocidentais-, mas da possibilidade de "falar com autoridade", isto é, o reconhecimento social de que o discurso tem valor e, portanto, merece ser ouvido." (2012: 19). Así, al tiempo que existe una preocupación en relación con la persona, también hay un trabajo alrededor de la constitución del sarau como un espacio propicio para adquirir autoridad a través de una serie de mecanismos de legitimación que apuntan a la conformación de un sentimiento de pertenencia y protección.

Este sentimiento de pertenencia se expresa, principalmente, a partir de lazos fuertes que se constituyen entre los participantes del sarau y que los llevan a ser considerados como de su familia. "Boa noite, família!" dicen algunos poetas al saludar a los presentes antes de declamar. "Sarau da Cooperifa é uma família, a família da gente, o pessoal do sarau se tornou uma família para a gente" dice Zé Batidão, el dueño del bar [Entrevista personal 2011].

A regularidade dos encontros poéticos, as conversas que precedem e sucedem os saraus, a intensa convivência, sobretudo entre as lideranças e poetas assíduos, bem como as relações sociais desenvolvidas, acarretaram laços fraternais entre os frequentadores e fizeram com que a Cooperifa seja vista também como uma família, que tem extensão da própria casa ao Bar do Zé Batidão, para alguns (Peçanha do Nascimento 2011: 93).

El micrófono cumple un papel importante en la consolidación de esos lazos, dado que es común que sirva para compartir vivencias y sentimientos íntimos, como la oficialización de compromisos maritales, la pérdida de un familiar, etc.; además, suelen festejarse los cumpleaños de los frecuentadores y los triunfos que cada uno de estos lleva a cabo, como el ingreso a una universidad.

El espacio del sarau es un espacio de contención, además, frente a situaciones difíciles y suelen armarse cadenas de solidaridad para apoyar a los frecuentadores que sufren algún inconveniente, como se puede leer en esta anécdota de Vaz:

Como emoção pouca, para nós, é bobagem, durante o sarau ligamos para a Ricarda, poeta da Cooperifa, que acabou de ser operada. Como a quarta-feira era dia da sua visita, e nós não podíamos visitá-la, ligamos para ela, e pelo viva-voz, ela emocionada nos disse que estava tudo bem e que tinha ficado muito contente pela nossa visita via satélite. Ao final, todos a aplaudiram e gritaram seu nome, para que ela pudesse entender que nenhum câncer pode com uma grande amizade. Força, guerreira! ${ }^{10}$

El sarau, así, funciona también como un lugar de

\footnotetext{
${ }^{10}$ Vaz Sérgio. "Os quatrocentos do Sarau da Cooperifa". Le Monde Diplomatique Brasil, 24 de julho de 2008. Disponível em: http://www. diplomatique.org.br/acervo.php?id=2886 (Acesso em setembro de 2015.)
}

pertenencia afectiva que les ofrece una protección y contención frente a las vulnerabilidades de la vida.

Otro ejemplo en este sentido se puede ver en la reacción que el sarau y el propio Sérgio Vaz tuvieron frente a una situación de discriminación que Preto Will, un poeta del sarau, sufrió en el metro. El 25 de octubre de 2011 Vaz publicó en su blog:

Preto Will, músico de Versão Popular e poeta da Cooperifa, foi expulso do Metrô Campo Limpo agora há pouco na porrada. É isso mesmo. Na porrada. (...) "Sai fora negão, se quiser vai de busão." (...) Partimos com advogados direto para a $37^{a}$ Delegacia que fica na região, mas sabe como é, vamos ficar na pressão, racismo é intolerável. Precisamos de todos os amigos, porque pode não ser pauta para grande mídia, mas é pauta no nosso cotidiano. ${ }^{11}$

Participar de un sarau, por lo tanto, conlleva a establecer una agencia con el grupo social negro, entendiendo por "agencia" un núcleo conceptual que tiene que ver con "visualizar al actor social desde su capacidad y competencias para movilizar recursos materiales y simbólicos para trasformar la realidad" (Reguillo 2000: 18). Esta agencia se traduce no solamente como la valoración de las manifestaciones culturales y la historia de la población negra en Brasil sino también como una relación de intercambio cuyo vector principal reposa en la idea de amparo y afecto.

El sentimiento de pertenencia en relación con la identidad negra y periférica que define a los saraus se profundiza, también, en un sentido más simbólico a partir del trabajo alrededor de la lengua, en sintonía con la tradición del rap. Las letras de rap y los poemas declamados en los saraus hacen uso permanentemente de un portugués tal como se lo escucha en las calles de los barrios periféricos. Hay una clara valorización de la tradición de la voz frente a la letrada no solamente como marca de estilo, sino también como marca identitaria. Uno de los versos de los Racionais MC's, "Negro Drama" del álbum que le siguió a Sobrevivendo no Inferno, Nada como um dia após do outro (2002), dice "gíria não, dialeto". Como bien explica Moassab (2008), la expresión remarca el lenguaje de la periferia como mecanismo de cohesión del grupo, vinculado a un territorio, a una experiencia y a un conocimiento común.

Las ceremonias de saludo y despedida que se ven, principalmente, en la zona externa del bar $^{12}$ donde

\footnotetext{
${ }^{11}$ Vaz, Sérgio. Racismo no metrô Campo Limpo. In: blog Colecionador de Pedras. Disponível em: http://colecionadordepedras1.blogspot. com.br/2011/10/racismo-no-metro-campo-limpo.html (Acesso em junho de 2016.)

12 El estar del lado de afuera del bar no significa no haber sido invitado al sarau. "O lado de fora é relativo", dice Zinho Trinidade (entrevista personal 2010). El sarau no sólo es el espacio del bar, es la extensión del bar también. Roberto da Matta en "La casa y la calle", refiriéndose a esos dos universos, dice que "el único modo de
} 
ocurre un sarau funcionan también como un refuerzo del sentimiento de pertenencia. Cuando las personas comienzan un encuentro de conversación o se alejan de él, se suele escuchar entre los hombres principalmente "É nóis"13, "Firmeza"14, "Tamo na luta", frases acompañadas por miradas fijas, un apretón de manos y luego un acercamiento lateral de los cuerpos, como golpeando hombros contrarios. En términos de Goffman, se podrían comprender tales "ceremonias" como un ritual, adquiriendo así otra significación más allá de la mera convención:

(...) los pequeños saludos, cumplidos y disculpas que salpican las relaciones sociales se pueden denominar "rituales de estatus" o "rituales interpersonales". Empleo el término ritual porque esta actividad, por informal y secular que sea, representa una forma en que el individuo debe proteger y designar las consecuencias simbólicas de sus actos, mientras se encuentra en presencia inmediata de un objeto que tiene un valor especial para él (1970: 56).

Este ritual en la puerta del sarau se impone con mayor fuerza que cuando se exhibe en una esquina cualquiera. La forma de saludar y de despedir que constantemente se ve en la puerta de los bares, el día de sarau tiene el valor particular de transmitir la idea de "tamo junto".

La premiación a los poetas que el sarau suele hacer con el Premio Cooperifa contribuye, asimismo, en la conformación de este lazo. Este premio surgió en el año 2005 con la finalidad de dar prestigio a los poetas, es decir, desde una función puramente individual, pero también para que "se estendesse para pessoas da comunidade e para todos aqueles que direta ou indiretamente ajudassem a periferia a se tornar um lugar melhor" (Vaz 2008: 184). En la primera edición hubo 106 premiados, 105 en la segunda y 125 en la última edición de 2008.

Dentre os agraciados com o Prêmio estão todos aqueles que desenvolveram alguma relação com a Cooperifa: poetas com frequência assídua aos saraus; outros escritores oriundos da periferia, como Ferréz, Sacolinha e Alessandro Buzo; rappers como GOG, Mano Brown, Dexter e Rappin' Hood; cantores como Lobão e Leandro Lehart; periódicos como as revistas Caros Amigos e Rap Brasil; equipamentos

entender correctamente este cuadro dicotómico es procurar verlo tanto en su lógica como en sus movimientos y articulaciones, pues en su dialéctica -en sus relaciones recíprocas- es donde podremos escapar del congelamiento al que con frecuencia conduce la visión formalista o taxonómica" (2002: 105).

13 "É nóis", "es nosotros", que se escucha permanentemente en la "periferia": se usa al reconocer un acto hecho para y por la periferia, se usa cuando se "conquista" un espacio por medio de una actividad o cuando se cierra un acuerdo que reafirma el capital "periferia".

14 "Firmeza" también se escucha permanentemente en la "periferia": se trata de un modo informal de saludar, usado también para cerrar un acuerdo o dar a entender que se apoya una acción. que receberam os cooperiféricos, ${ }^{15}$ como a Casa das Rosas e a Casa de Cultura M'Boi Mirim; ONGs como Ação Educativa, entre outros, divididos nas categorias literatura, eventos, teatro, personalidades importantes, música, projetos, jornalismo, fotografia, educação, comunicação e comunidade" (Nascimento 2011: 101).

Se trata, por un lado, de un tipo de reconocimiento individual a cada premiado por la contribución que realiza al Sarau, pero también es una estrategia de reconocimiento propia del grupo en tanto grupo, dado que consiste en una valoración simbólica de los distintos papeles que hacen posible el sarau, profundizando, así, el sentimiento de pertenencia.

Por último, las fórmulas más repetidas para conformar un sentimiento de pertenencia que valorice y autorice las voces de los saraus son el silencio y el aplauso. El silencio sepulcral y la ovación indistinta después de cada poesía llaman fuertemente la atención a quien se aproxima a los saraus por primera vez, dado que entre un poema y otro pocas veces se producen grandes diferencias en la reacción del auditorio. Como fue descripto al comienzo de este capítulo, las palabras efusivas se desprenden siempre luego de cada poema y la escucha atenta durante la declamación es igual ante todos los casos. Resulta necesario comprender, de todos modos, que esos aplausos y silencios no están impulsados por la noción de "gusto". La idea de "gusto" letrado, individualizado y fuertemente asociado a la sensibilidad personal no es la que está detrás de ellos. Ninguna de estas dos reacciones está impulsada desde la idea de un observador/receptor individual que moviliza su juicio estético. Pensar dichas prácticas desde ese enfoque letradocéntrico llevaría a afirmar una ingenuidad de la mirada periférica en relación con las formas estéticas. Lo que ellas expresan, más bien, es una acción colectiva que refuerza la construcción de una persona periférica resignificada desde el orgullo, despojada de la comparación denigrante respecto de los sujetos de tradición letrada.

Entonces, el aplauso, lo mismo que el silencio, se asocian aquí no a un acto individual sino relacional. En este sentido, puede entenderse la afirmación que se reitera en Cooperifa "O silêncio é uma prece", ya que, de acuerdo con Marcel Mauss, la plegaria no es simplemente un fenómeno individual, una "efusión del alma" o un "grito de un sentimiento", sino, antes que nada, resulta un fenómeno colectivo (1979: 117) que, como tal, cumple una función en la economía moral de las relaciones sociales. Dicho de otro modo, el silencio y el aplauso funcionan como un lenguaje corporal que actúa en la dinámica colectiva del sarau imprimiendo una idea de "respeto" fuertemente vinculada al reconocimiento de las

\footnotetext{
${ }^{15}$ A adjetivação derivada do termo Cooperifa também dá conta de um sentimento de pertença, já que a ideia de "cooperiférico" remete justamente ao fato de que faz parte desse coletivo.
} 
capacidades de los frecuentadores, "respeto" entendido en el sentido de "amor propio", el "amour de soi" de una persona, que consiste en "la aceptación elegante de la edad, la situación social o la confianza en las capacidades personales (...)" (Sennett 2003: 100).

En este punto es importante señalar que, aunque en el sarau el silencio y el aplauso son acciones colectivas no ligadas al gusto personal, esto no quiere decir que no haya conciencia del juicio estético en esos espacios, sino que la forma de manifestarlo no responde a los rituales de los círculos letrados. Alisson da Paz, un poeta y asiduo frecuentador de los saraus de la periferia, dice que lo que más lo entusiasma como poeta es cuando las personas reaccionan de modo no esperado frente a su declamación:

Eu gosto de falar assim: eu preferia um minuto de silêncio do que um minuto de aplauso. Por isso, eu apresento umas poesias para causar silêncio, pra fazer que aquilo ecoe. A fala é o feminino do falo e os dois têm um ato de penetração. Então, quando eu vou declamar um poema, eu quero penetrar no ouvido daquelas pessoas, me imaginar nelas, quero chegar nelas. E o silêncio é quando eu sinto que eu cheguei nas pessoas, quando eu percebo que fica alguns segundos de silêncio, que você vê o silêncio, que você vê o silêncio ganhando corpo. Aí, depois, se rola aplauso ou não, pra mim não faz muita diferença. Mas quando rola o silêncio, aí você fala assim: "Porra! Cheguei! Essa poesia é comunicável". (Entrevista personal 2010)

Habría, de acuerdo con la afirmación de Alisson da Paz, dos formas de silencio: el silencio durante la declamación impulsado por el respeto colectivo y el posible silencio posterior a ella, impulsado por el juicio estético individual. Tanto en uno como en otro caso el silencio no remite nunca a la idea de "falta", sino que tiene una función comunicativa poderosa, tanto individual como colectiva. Es así como el silencio en los saraus adquiere un sentido pleno. La distinción de los modos y funciones del silencio y del aplauso resulta clave para observar que en los saraus de la periferia funciona también una idea de "gusto", pero se expresa con mecanismos corporales diferentes a los de los espacios de tradición letrada.

\section{Taller de ciudadanía}

El silencio, fórmula central de todos los saraus, en este sentido, no tiene que ver con la falta de palabra, sino que habilita la escucha y la construcción de una voz propia, dado que solo quien escucha puede hablar con voz propia. El espacio del sarau se vuelve, así, un espacio de entrenamiento de interlocutores calificados en el marco de una acción colectiva, de ahí que Vaz vincule esta práctica del silencio con la construcción de ciudadanía en el sarau:
Ali no Sarau da Cooperifa é assim: é uma oficina de cidadania. Só que o máximo que você tem que fazer é fazer silêncio para ouvir o próximo, então isso já te faz refletir. Muitas vezes você passa o tempo falando, falando, [e] nunca ouve. E ali as pessoas têm a humildade de parar de falar para ouvir. Então ali, além de uma escola poética, é uma escola de cidadania. Quer dizer, não é uma coisa imposta. Mas é o ar que se respira ali. Essa é a ideia. (Entrevista personal 2010)

La idea de ciudadanía que se utiliza aquí se entiende de manera expandida, dado que implica no solamente la relación Estado-ciudadano, sino también la relación ciudadano-ciudadano. La ciudadanía desde ese punto de vista es algo que se construye de forma plural, no de forma pasiva (esto es, como algo que se recibe) y el espacio del sarau parece ser el privilegiado para ello. Pero no como espacio de instrucción sobre la "cultura ciudadana", lo que implicaría conformarse con lo establecido, sino desde una idea de "ciudadanía cultural", esto es, a partir un tipo de representación que considere las pertenencias y los anclajes culturales como componentes indisociables de la definición de ciudadanía: "la cultura como plataforma para la ciudadanía o en otras palabras, la consideración de las pertenencias y adscripciones de carácter cultural como componentes indisociables en la definición de ciudadanía" (Rosaldo 2000). Se trata no solamente del derecho a la igualdad, sino también del derecho a la diferencia: la posibilidad de poder pronunciarse afirmativamente con respecto a la propia identidad y el propio cuerpo, y ser respetado por esas certezas. De esta manera, se vuelven visibles los olvidos y las exclusiones de las etapas civiles y políticas en la configuración de lo ciudadano. El sentimiento de pertenencia, entonces, se articula también a un nivel más abarcativo, ligado a la idea de ciudadanía.

La pregunta que surge, de todos modos, es ¿de qué manera funciona ese tipo de ciudadanía fuera del sarau? Porque en el contexto del sarau la ciudadanía pareciera ser una condición sub-liminal, esto es, de acuerdo con la teoría antropológica (Turner 1999), que no está ni en un lugar ni en un tiempo.

Então a gente prática essa cidadania de uma maneira subliminar, não é uma coisa imposta. É uma coisa que a pessoa tem que pegar no ar, porque a gente não quer doutrinar ninguém: faz isso, faz aquilo. O sistema funciona para que todo mundo seja igual. Eu acho que sempre tem assim alguém que é mais do que o outro, porque essa é a condição do ser humano, a vaidade e a mediocridade é democrática, né? Mas aqui a gente não incentiva isso, de forma alguma. (Sérgio Vaz entrevista personal 2010)

Dentro del sarau, de acuerdo con la afirmación de Vaz, funciona cierta idea de igualdad que no se corresponde con el afuera. Esta sería la gran paradoja de la ciudadanía propuesta en estos espacios que nos lleva a preguntarnos 
hasta qué punto los participantes no se vuelven más que sujetos políticos, objetos de políticas públicas, dado que la distancia con respecto a ese "Otro" se sigue manteniendo.

\section{Consideraciones finales}

Por medio de este artículo traté de dar cuenta del papel múltiple que cumple la literatura en los saraus de las periferias de São Paulo, paralelamente a la preocupación estética. La literatura en dichos espacios es considerada como un medio facilitador para proyectar ser una "persona" con una valoración específica de sí mismo en el marco de un "colectivo" que le otorga protección y promueve el desarrollo de un sentimiento de pertenencia y de "ciudadanía".

El propósito de la asociación de la idea de literatura con las nociones de persona, de colectividad y de ciudadanía tiene que ver con ir más allá de su asociación, común al analizar las producciones de la literatura de las periferias, con la noción de identidad, que podría confundir la propuesta con una posición reformista o podría llevarnos a un análisis sustancialista que nos impediría percibir la multiplicidad del fenómeno. La literatura en estos espacios no tiene que ver tanto con la formación de identidades, sino más bien con la potencialidad de los aspectos propios de la vida en la periferia.

Por otro lado, la reconstrucción de esos usos en el espacio de los saraus restituye una visión diferenciada sobre aquellas interpretaciones que parten de una idea pre-dada de lo que es literatura, que suele funcionar como una como una categoría bastante limitada a ciertos grupos, que no alcanza para dar cuenta de la variedad de prácticas verbales producidas en otros ámbitos.

En suma, el estudio de los usos del término literatura en los saraus de las periferias de São Paulo se nos plantea como privilegiado para repensar las preguntas alrededor de los posicionamientos de los sujetos y de los criterios de valoración acerca de lo que se entiende por literatura.

Buenos Aires, 9 setiembre de 2016

\section{Bibliografía}

Bourdieu, P. (1997). Razones Prácticas, Barcelona, Anagrama.

Dalcastagnè, R. (2012). Literatura Brasileira contemporânea: um território Contestado, Rio de Janeiro, Horizonte.

Damatta, R. (2002). Carnavales, Malandros y Héroes. Hacia una sociología del dilema Brasileño, México D.F., Fondo de Cultura Económica.

De Certeau, M. (2006). La debilidad de creer, Buenos Aires, Katz.

Goffman, E. (2009). La presentación de la persona en la vida cotidiana, Buenos Aires, Amorrortu.

Goffman, E. (2010) Estigma. La identidad deteriorada, Buenos Aires, Amorrortu.

Goffman, E. (1970). El ritual de interacción, Buenos Aires, Tiempo Contemporaneo.

Mauss, M. (2003). "A persona". En Sociologia e antropologia, São Paulo, Cosac \& Naify.

Moassab, A. (2008). Brasil Periferia(s). "A comunicação insurgentedo Hip-Hop". Facultad de Ciencias Sociales. Pontifícia Universidad Católica de San Pablo. Tesis de Doctorado. Biblioteca Pontifícia Universidad Católica de San Pablo.

Peçanha Do Nascimento, É. (2011). "É tudo nosso! Produção cultural da periferia paulistana" Programa de Pos-graduação da Faculdade de Filosofia, Letras e Ciências Humanas da Universidade de São Paulo. Tese de Doutorado. Biblioteca USP

Salles, E. (2007). Poesia revoltada, Rio de Janeiro, Aeroplano.

Senett, R. (2003). El Respeto. Sobre la dignidad del hombre en un mundo de desigualdad, Barcelona, Anagrama

Rosaldo, R. (2000). La pertenencia no es un lujo: Procesos de ciudadanía cultural dentro de una sociedad multicultural. Desacatos, núm. 3, s/n

Tennina, L. (2013). Saraus das periferias de São Paulo: poesia entre tragos, silêncios e aplausos, Estudos de Literatura Brasileira Contemporânea, Brasília, nº 42.

Turner, V. W. (1999). La selva de los símbolos, Madrid, Siglo XXI. 